\title{
BCCN4
}

\section{LOCAL BUCKLING OF PULTRUDED GFRP I-SECTION SUBJECT TO BENDING}

\author{
Everton de S. Vieira ${ }^{(1)}$, Janine D.Vieira ${ }^{(2)}$ and Daniel C. T. Cardoso ${ }^{(1)}$ \\ (1) Department of Civil and Environmental Engineering, Pontifícia Universidade Católica do \\ Rio de Janeiro, Brazil \\ (2) Department of Civil Engineering, Universidade Federal Fluminense, Niteroi, Brazil
}

https://doi.org/10.21452/bccm4.2018.06.05

\begin{abstract}
The use of pultruded glass fiber reinforced polymer (pGFRP) has increased significantly in the last few years, especially in aggressive environments. The structural performance of pGFRP members is strongly dependent on their buckling behavior, because of the association of low elastic properties and relatively thin-walled sections adopted. The aim of this study is to present the results of an ongoing experimental work focused on evaluating the local buckling behavior of GFRP I-beams subject to 4-point bending tests. Lateral deflections were measured with displacement transducers and the curvature at compression flange during loading was measured with back-to-back strain gages. A finite element model using actual material properties and bracing conditions was adopted to ensure behavior governed by local buckling and to determine critical bending moment. The influence of web-to-flange rotational stiffness on the behaviour is discussed and, finally, experimental critical loads obtained using Southwell and Koiter techniques are compared to those obtained using analytical expressions recently proposed in literature and to computational analysis
\end{abstract}

\section{INTRODUCTION}

Pultruded glass fiber-reinforced polymer (pGFRP) members had their first applications in aerospace industry followed by oil and automotive industries. In the last years, the use of pGFRP increased in structural engineering because of its good performance in aggressive environments and high tensile and compressive strengths (parallel to fiber direction), comparable with steel. However, the association of the low modulus of elasticity in the longitudinal direction - about 1/8 that of steel - to the relatively thin-walled sections adopted and high material anisotropy makes pGRFP members susceptible to instability problems and significant interaction between local and global buckling modes [1].

Several authors have dedicated efforts to study local buckling behavior of pGFRP members subject to compression with different cross-sections (e.g. [2,3,1]). However, only a few have been exclusively dedicated to experimentally the local buckling in bending. In the 
early 1990's, Barbero et al. [4] conducted a series of tests in pGFRP beams subject to bending. Specimens were laterally braced at mid-span and the authors observed that failure by local buckling governed the behavior. Bank et al. [5] performed four-point bending tests in beams designed to fail in local buckling and reported typical failure mode by tearing along the web-flange junction at the constant-moment region. Later, Bank et al. [6] reviewed experimental data of three beams and proposed an appropriate technique to determine the critical load accounting for the non-linear behavior and avoiding overestimated results. Finite element method (FEM) analyses were also carried out to show that anisotropy and inhomogeneity of pultruded material may affect significantly local buckling behavior. Recently, Vieira et al. [7] reported the results of an experimental study aiming to investigate the flexural behavior of GFRP beams for a variety of section geometries and spans. The work showed different buckling modes and the experimental results were compared with those obtained using design methods available in standard under development (ASCE [8], EUR27666 [9]) as well as to the equation proposed by Kollar [10] and to Finite Strip Method (FSM). According to the authors, the design methods were found to be conservative. It is also worth reporting the interesting study carried out by Kubiak et al. [11] in non-pultruded composite channel sections. To ensure local buckling due to 'pure' flexure, i.e. avoiding influence of shear in the buckling mode, rigid blocks were adopted at the shear spans and, to account for the non-hyperbolic load-deflection behavior, experimental critical loads were obtained using Koiter's technique.

Several closed form equations to calculate the critical load for different loading conditions are available in literature [10, 12, 13, 14]. Kollar [10], for instance, presented explicit expressions considering the cross-section comprised of orthotropic plates with rotationally restrained edges. The method allows considering different cross-sections and loading conditions and has been validated for I-sections, resulting in its inclusion in the latest versions of standards under development. Closed form equations for I-section beams subject to pure bending are also presented by Ascione et al. [13] and Cardoso and Vieira [14]. In these works, equations were obtained using energy methods along with assumed approximate buckled shapes and good results were obtained when compared to numerical methods. Approaches considering interaction between flange and web lead to superior agreement and will soon prevail over the simple but old-fashioned approach where web-to-flange junction is assumed as hinged. Another important parameter is the flexibility of the flange-to-web junction, [15]. To date, there is no explicit equation accounting for this flexibility, although significant reduction in critical loads has been reported in literature [16].

The flexural performance of pGFRP is dependent on its buckling behavior. Due to its orthotropic properties, formulations proposed for isotropic materials on instability studies give unreliable results. The aim of this paper is to present results of an ongoing research on flexural behavior of pultruded GFRP I-sections. Results from tests on I-sections having flange-to-web width ratio equal to 1.0 are reported and compared to those obtained using finite element method (FEM) and analytical expressions proposed Cardoso and Vieira [15], as well as by EUR 27666 [9] and ASCE [8]. The influence of the flexibility of the web-to-flange junction is also discussed

\section{EXPERIMENTAL PROGRAM}

\subsection{Material Characterization}

The wide flange pultruded profiles with section depth, d, equal to flange width, bf, used in this study were made with vinyl ester resin and E-glass fiber. In order to obtain the relevant properties of the material, specimens were extracted from flanges and web and mechanical characterization was carried out. The average values (and COV in parentheses) of the experimental mechanical properties as well as those reported by the manufacturer are 
presented in Table 1. It is important to mention that all moduli in flexure are related to the bending of constituent walls and that the transverse modulus, $\mathrm{E}_{\mathrm{T}, \mathrm{f}}$, was determined with a non-standard test since the geometry of the pultruded profile did not allow extraction of specimens with standards dimensions. Figure 1 shows the tests performed for mechanical characterization of the pultruded material.

Table 1: Mechanical properties of GFRP profiles, in MPa.

\begin{tabular}{lcccc}
\hline \multirow{2}{*}{ Mechanical properties } & \multirow{2}{*}{ Test method } & \multicolumn{2}{c}{ Experimental values (COV) } & Manufacturer \\
\cline { 3 - 4 } & & Flange & Web & reported \\
\hline Longitudinal modulus in tension, $\mathrm{E}_{\mathrm{L}, \mathrm{t}}$ & ISO 527-4 & $32653(0.11)$ & $26350(0.03)$ & 17260 \\
Longitudinal modulus in compression, $\mathrm{E}_{\mathrm{L}, \mathrm{c}}$ & ASTM D6641 & $30401(0.17)$ & $28328(0.09)$ & - \\
Longitudinal modulus in flexure, $\mathrm{E}_{\mathrm{L}, \mathrm{f}}$ & ISO 14125 & $19854(0.25)$ & $17425(0.01)$ & 10984 \\
Transverse modulus in flexure, $\mathrm{E}_{\mathrm{T}, \mathrm{f}}$ & non-standard & $7867(0.05)$ & - & 5492 \\
Shear modulus, $\mathrm{G}_{\mathrm{LT}}$ & ASTM D5379 & $2298(0.42)$ & $2374(0.11)$ & - \\
Longitudinal strength in tension, $\mathrm{F}_{\mathrm{L}, \mathrm{t}}$ & ISO 527-4 & $425(0.04)$ & $330(0.15)$ & 287 \\
Longitudinal strength in compression, $\mathrm{F}_{\mathrm{L}, \mathrm{c}}$ & ASTM D6641 & $275(0.05)$ & $370(0.15)$ & 287 \\
Longitudinal strength in flexure, $\mathrm{F}_{\mathrm{L}, \mathrm{f}}$ & ISO 14125 & $470(0.09)$ & $477(0.04)$ & 287 \\
\hline
\end{tabular}

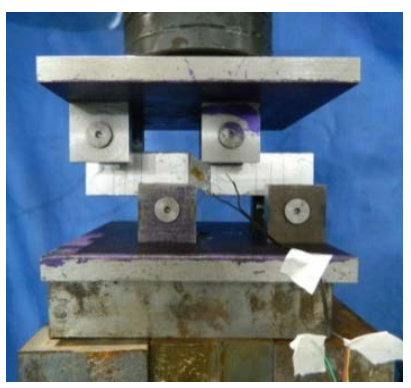

(a) Isosipescu test

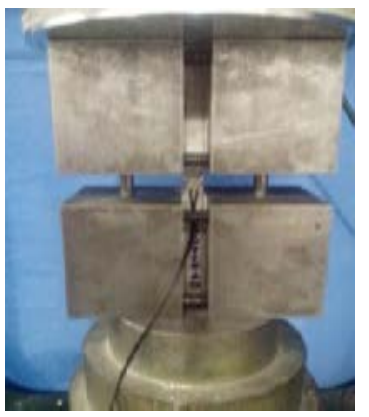

(d) Compression test

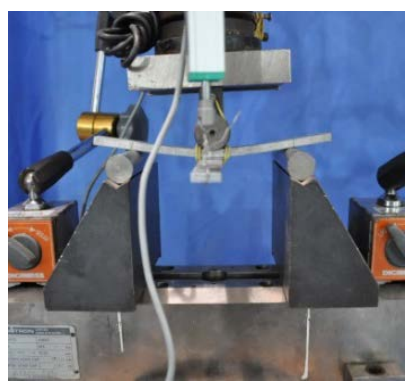

(b) Three point flexure test

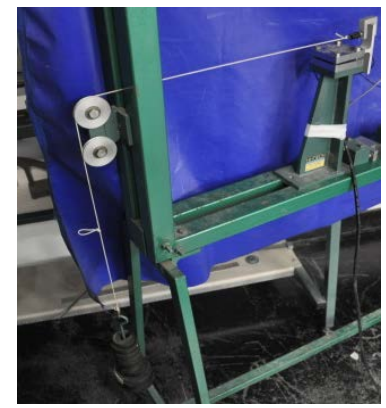

(e) and (f) Transverse flexure test

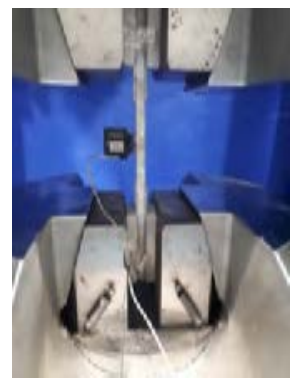

(c) Tensile test

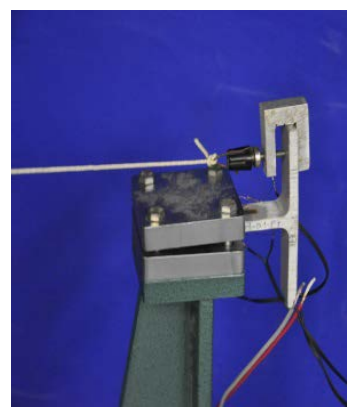

ests

\subsection{Rotational spring constant $(\mathrm{k} \theta)$}

It has been shown in literature that the rotational stiffness of the web-to-flange junction may affect significantly the critical load and buckling mode $[15,16]$. In this work, an experimental characterization of the rotational spring constant was carried out. Three 'tee' specimens $85-\mathrm{mm}$ wide extracted from the pultruded profiles were used. The flange of the specimen was clamped at a test frame using rigid aluminum bars to ensure no displacement and steel plates were attached to the web to assure negligible plate bending during the tests. 
To measure the lateral displacement, a displacement transducer was placed at the free end of the 'tee' stem, in the direction of applied load. The load was applied using dead weights and was incremented manually. Figure 2 shows the set-up adopted for the experimental test. The average value for $\mathrm{k} \theta$ obtained was $10085 \mathrm{~N} . \mathrm{mm} / \mathrm{mm} / \mathrm{rad}$.

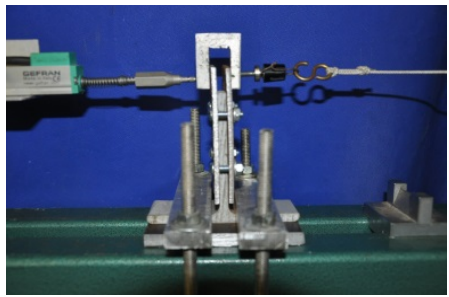

(a)Lateral view

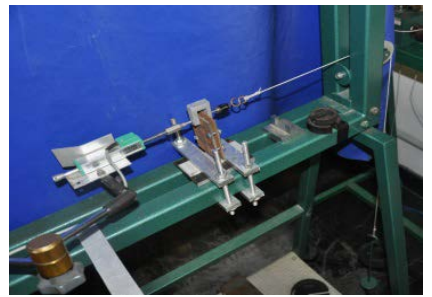

(b) Overview

\subsection{Flange Local Buckling (FLB) - Four-point bending test}

For the flange local buckling (FLB) investigation, three I-sections with nominal dimensions $102 \times 102 \times 6 \mathrm{~mm}$ ( $\mathrm{d} \times \mathrm{bf} \times \mathrm{t}$, where $\mathrm{t}$ is the uniform thickness) with a flange slenderness, bf/2t, of 8.5 were tested. Four-point bending tests over a span of $1100 \mathrm{~mm}$ consisting of two $310-\mathrm{mm}$ shear spans and a $480-\mathrm{mm}$ constant moment region were carried out. In all tests, lateral supports were provided near supports and loading points to prevent lateral torsional buckling (LTB) and distortion. For this purpose, steel plates coated with teflon to avoid the friction between the profile and the plates were used. A narrow neoprene layer was used at the loading points to concentrate loads over web, i.e. without introducing transverse flexure on flanges. To monitor the onset and development of FLB, back-to-back strain gages were applied to both tips of the compression flange, at the middle of the constant moment region. Draw-wire transducers were used to measure the vertical deflection and the lateral displacement of the beam at mid-span.

All the tests were carried out using a $1000 \mathrm{kN}$ capacity servo-hidraulic MTS actuator with a displacement control of $0.6 \mathrm{~mm} / \mathrm{min}$ up to failure. Figure 3 shows the setup for the flexural tests.

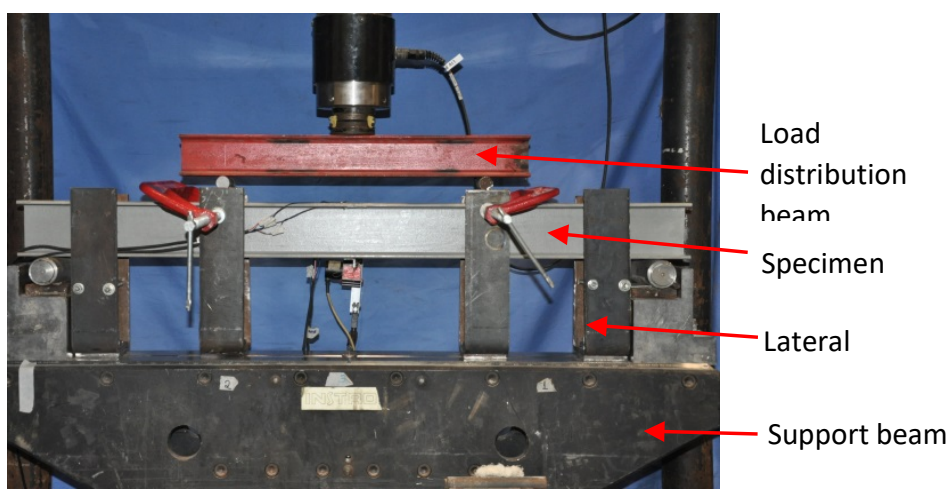

(a) front-view

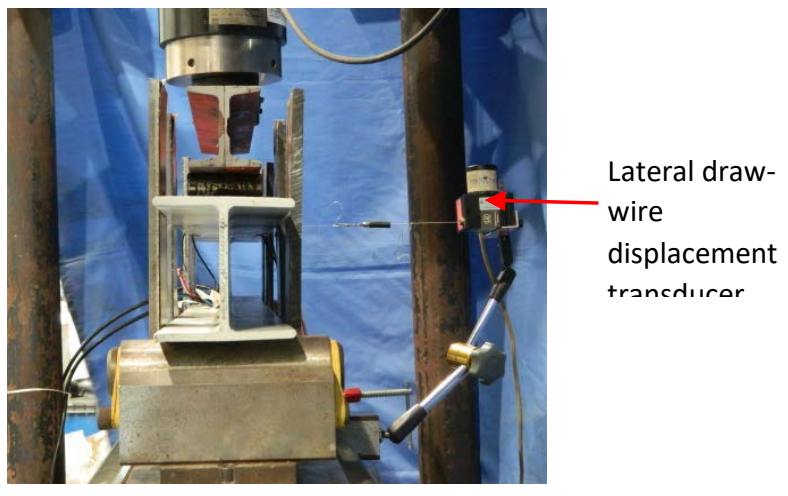

(b) lateral view

Figure 3: Set-up for pGRFP flexural tests.

\section{$2.4 \quad$ Finite Element Method (FEM)}


In order to predict the local buckling critical moment, linear eigenvalue FEM analysis was carried out using Abaqus 6.13.1 [17] software. The model was discretized with shell elements S8R5 and average experimental mechanical properties were used. To represent the rotational stiffness at the junction, flange and web were joined using connector-type elements with rotational spring about axis $\mathrm{Z}$ defined according to the experiments. To simulate the lateral supports, the displacements in $\mathrm{X}$ direction were restrained at both flanges. Translations in vertical direction $(\mathrm{Y})$ were restrained at both ends whereas translation at $\mathrm{Z}$ direction was included in one of the ends. Figure 4 shows the model of the beam with their boundary conditions. Figure 5 illustrates the first buckling mode obtained from FEM analysis.

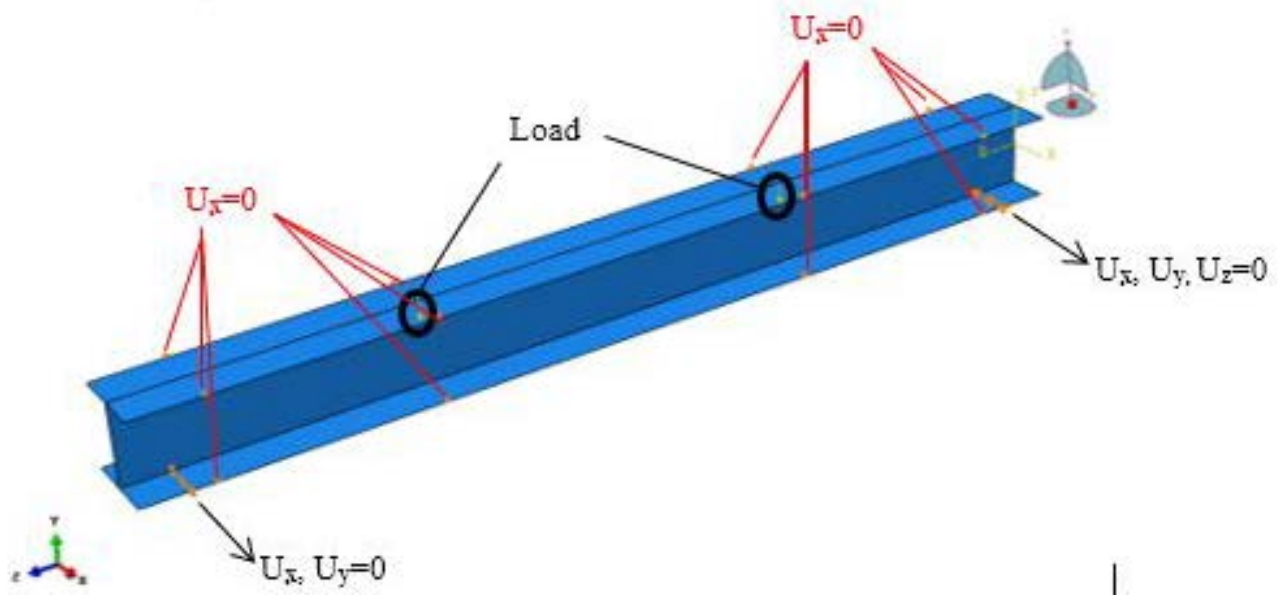

Figure 4: Boundary conditions of the beam implemented in FEM

\section{RESULTS ANS DISCUSSIONS}

Representative experimental moment vs vertical and moment vs lateral deflections are reproduced in Figure 6a and 6b, respectively. All the tests exhibited negligible lateral motions prior to local buckling. After the formation of local buckling waves, lateral deflections resulting from loss of stiffness can be observed. Failure finally results from an interaction between FLB and LTB, leading to premature failure and unnoticeable post-buckling reserve of strength. This phenomenon can be clearly observed from moment-lateral deflection shown in Figure 6b as well as from the differences in non-dimensional curvature, $\Phi$ (equal to strain at top minus strain at bottom of flange), obtained for the pairs of strain-gages for each side of the flange presented in moment vs non-dimensional curvature shown in Figure 6c, which suggests a greater compression stress in one side of the flange and a relief on the opposite side. Larger amplitude on the more compressed side could also be observed during tests, as shown in the typical buckling mode illustrated in Figure 7. All beams tested exhibited flangeto-web tearing failure. 


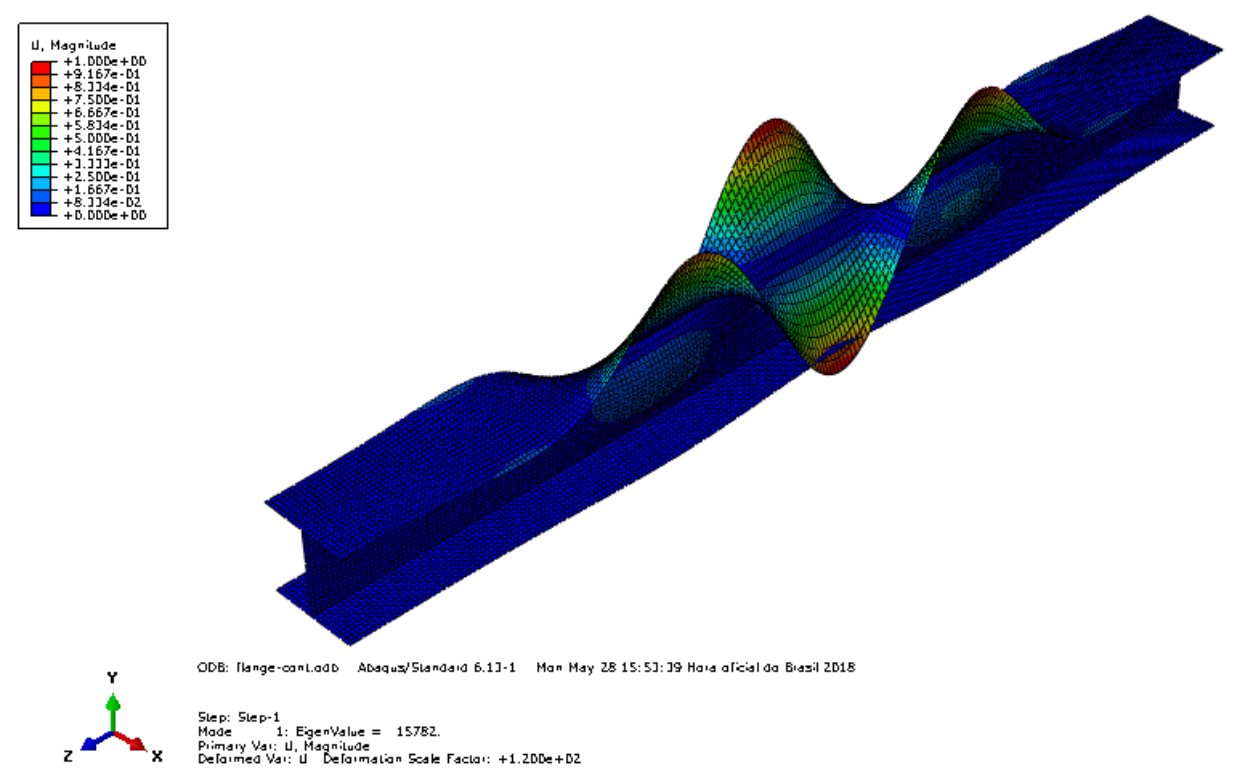

Figure 5: buckling mode of four-point bending FE model

The experimental critical FLB moments obtained using Southwell and Koiter techniques and the results obtained from analytical and computational analyses (FEM) are present in Table 2. In all analyses, nominal section dimensions were used. It is important to mention that Koiter's approach take into account the post-buckling behavior whereas Southwell is usually valid for columns with hyperbolic buckling behavior. A good agreement was achieved between experimental results and those obtained with ASCE Pre-standard [8], Cardoso and Vieira [14] and with Finite Element Method (FEM), whereas significant lower critical stress was obtained using EUR 27666 [9]. It is important to note that a closer prediction was expected using FEM model and differences may be explained by a low rotational stiffness and/or shear modulus adopted in the model, suggesting that more characterization tests are necessary to obtain reliable properties. It can also be highlighted that the method proposed by Cardoso and Vieira [14] is based on energy approach and assumes full compatibility of rotation between flange and web, therefore resulting in greatest prediction among all methods, although relatively close to the experimental results.

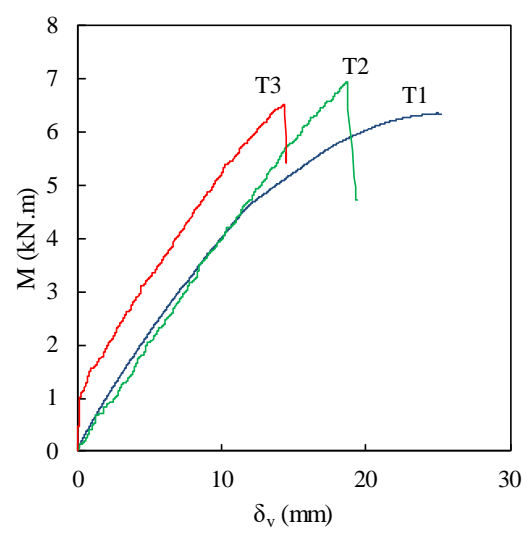

a) moment vs vertical deflection

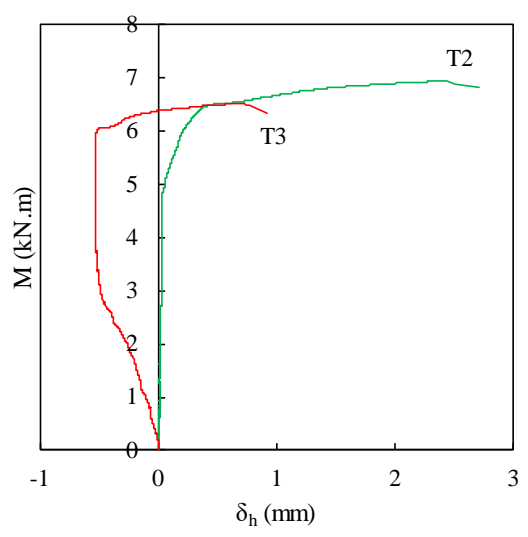

b) moment vs horizontal deflection

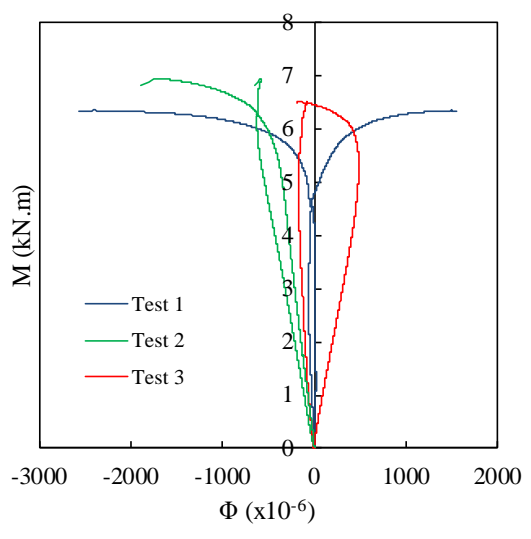

c) moment vs non-dimensional curvature

Figure 6: Experimental results. 
Table 2: Critical moments in N.m for various analyses.

\begin{tabular}{|c|c|c|c|c|c|c|c|c|c|}
\hline \multicolumn{2}{|c|}{ Experimental (COV) } & \multicolumn{2}{|c|}{ FEM } & \multicolumn{2}{|c|}{$\begin{array}{l}\text { Cardoso and Vieira } \\
\text { (2017) }\end{array}$} & \multicolumn{2}{|c|}{ EUR 27666 (2016) } & \multicolumn{2}{|c|}{ ASCE (2010) } \\
\hline Southwell & Koiter & $\mathrm{M}_{\mathrm{cr}}$ & pred./exp. & $\mathrm{M}_{\mathrm{cr}}$ & pred./exp & $\mathrm{M}_{\mathrm{cr}}$ & pred./exp. & $\mathrm{M}_{\mathrm{cr}}$ & pred./exp. \\
\hline $\begin{array}{c}5502 \\
(0.069)\end{array}$ & $\begin{array}{l}5509 \\
(0.12)\end{array}$ & 4894 & $0.81-0.96$ & 5754 & $0.96-1.13$ & 4424 & $0.74-0.87$ & 5523 & 0.92-1.09 \\
\hline
\end{tabular}

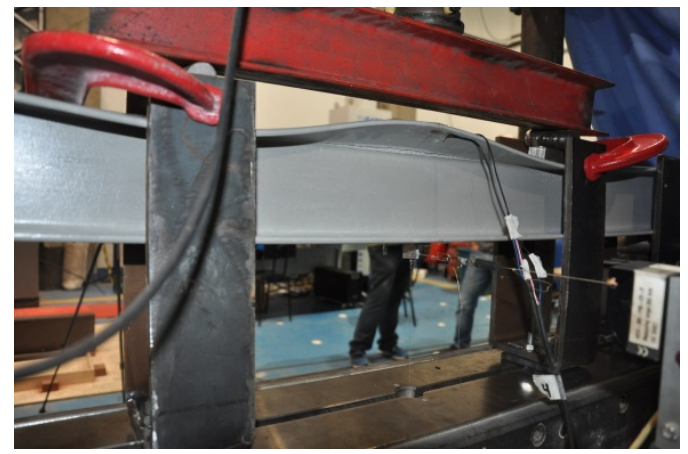

a) Flange local buckling at constant region moment

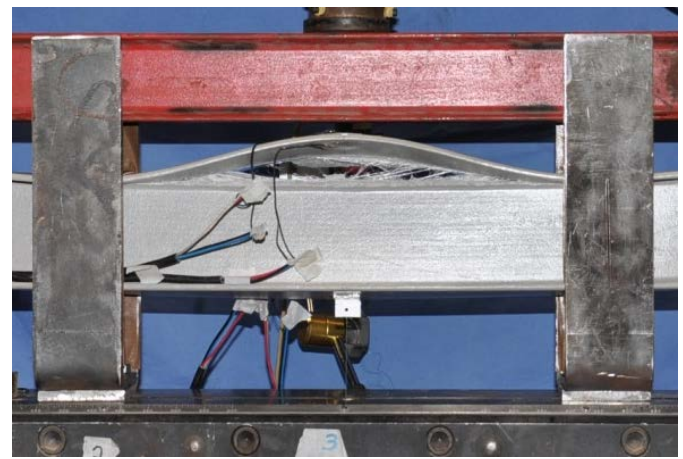

c) Web-junction tearing failure

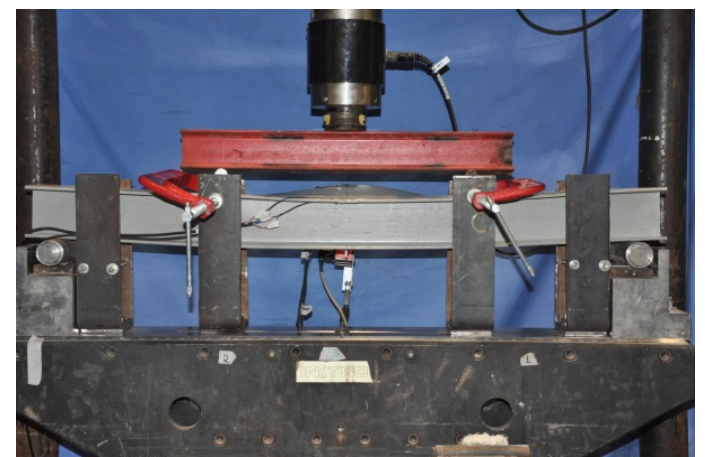

b) Differences in the amplitude of halfwaves for both sides of compression flange.

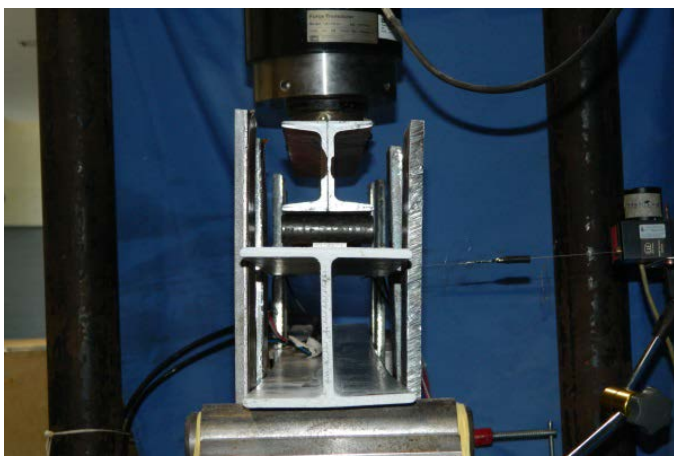

d) Compression flange rotation

Figure 7: Local flange buckling observed in the experimental tests

\section{CONCLUSIONS}

- This paper presented the results of an ongoing experimental work with the objective to evaluate the local buckling behaviour of GFRP I-beams subject to four-point bending tests. The experimental program included mechanical characterization tests and a simple nonstandard test to obtain the rotational spring constant was proposed.

- The beam tests showed that the rotational stiffness of web-to-flange junction influences critical moment and buckling behaviour. A FEM model of the beam was implemented with the rotational spring constant and a good correlation was observed, although FEM results in lower critical stress, which may be attributed to inherent variations of material properties. More characterization tests must be carried out to obtain reliable properties and, therefore, a closer agreement between FEM and experiments. 
- The equations proposed by ASCE [8] and by Cardoso and Vieira [14] presented good agreement with the experimental results. On the other hand, the critical stress obtained using the equation proposed in the EUR 27666 [9] underestimates significantly the experimental results. It is important to mention that all theoretical approaches studied neglect the rotational stiffness of the web-to-flange junction and more tests are necessary to validate the methods for general conditions.

- The failure modes were similar in all tests with rupture in web-flange junction. This type of failure is expected since it can be affected by presence of the resin-rich zone which interfere in the arrangements of the fibers and local imperfections due to the pultrusion process.

\section{ACKNOWLEDGEMENTS}

The first author thanks to CAPES (Coordenação de Aperfeiçoamento de Pessoal de Nivel Superior) for financial support. All authors wish to thanks Stratus Compostos Estruturais Ltda for supplying the GFRP profiles used in this work.

\section{REFERENCES}

[1] Cardoso D., Harries K. and Batista E. "Compressive local buckling of pultruded GFRP Isections: development and numerical/experimental evaluation of an explicit equation”. ASCE Journal of Composites for Construction, 19(2), (2015)

[2] Tomblin, J. and Barbero, E. "Local buckling experiments on FRP columns". Thin-walled structures, 18(2), (1994) 97-116.

[3] Turvey, G. and Zhang, Y. “A computational and experimental analysis of the buckling, postbucking and initial failure of pultruded GRP columns”. Computers and Structures, 84(22), (2006a) 1527-1537.

[4] Barbero, E., Fu, S., and Raftoyiannis, I. "Ultimate bending strength of composite beams”. Journal of Materials in Civil Engineering, 3(4), (1991) 292-306.

[5] Bank, L., Nadipelli, M., Gentry, T.. "Local buckling and failure of pultruded fiber-reinforced plastic beams”. Journal of Engineering Materials and Technology, 116(2), (1994) 233-237.

[6] Bank, L., Yin, J., and Nadipelli, M.. "Local buckling of pultruded beams-Nonlinearity, anisotropy and inhomogeneity”. Construction and Building Materials, 9(6), (1995) 325-331.

[7] Vieira, J., Liu, T., and Harries, K.. "Flexural stability of pultruded glass fibre-reinforced polymer I-sections". Proceedings of the Institution of Civil Engineers - Structures and Buildings, (2017) 1-12.

[8] ASCE - American Society of Civil Engineers (2010). "Pre-standard for load and resistance factor design (LRFD) of pultruded fiber reinforced polymer (FRP) structures”. ASCE, Reston, VA, USA.

[9] Ascione, L. et al.. "Prospect for new guidance in the design of FRP: Support to the implementation and further development of the eurocode". Publications Office of the European Union, Brussels, Belgium, Report EUR 27666, (2016).

[10] Kollár, L. P.. "Local buckling of fiber reinforced plastic composite structural members with open and closed cross sections”. Journal of Structural Engineering, 129(11), (2003) 15031513.

[11] Kubiak, T., Kolakowski, Z., Swiniarski, J., Urbaniak, M., and Gliszczynski, A.. "Local buckling and post-buckling of composite channel-section beams-Numerical and experimental investigations”. Composites Part B: Engineering, 91, (2016) 176-188.

[12] Mottram, J. T.. "Determination of critical load for flange buckling in concentrically loaded pultruded columns". Composites Part B: Engineering, 35(1), (2004) 35-47.

[13] Ascione, F., Feo, L., Lamberti, M., Minghini, F., and Tullini, N.. “A closed-form equation for the local buckling moment of pultruded FRP I-beams in major-axis bending”. Composites Part B: Engineering, 97, (2016) 292-299. 
$4^{\text {th }}$ Brazilian Conference on Composite Materials. Rio de Janeiro, July $22^{\text {nd }}-25^{\text {th }}, 2018$

[14] Cardoso, D. C., and Vieira, J. D.. "Comprehensive local buckling equations for FRP I-sections in pure bending or compression”. Composite Structures, 182, (2017) 301-310.

[15] Turvey, G., and Zhang, Y.. "Characterization of the rotational stiffness and strength of webflange junctions of pultruded GRP WF-sections via web bending tests". Composites Part A: applied science and manufacturing, 37(2), (2006b) 152-164.

[16] Ascione, L., Berardi, V. P., Giordano, A., and Spadea, S.. "Local buckling behavior of FRP thin-walled beams: a mechanical model”. Composite Structures, 98, (2013) 111-120.

[17] ABAQUS. Software Documentation. Version 6.13.1 by SIMULIA, (2013). 